\title{
CELL-CELL COMMUNICATION PREDICTS AGING, SENESCENCE AND DEATH: AN INTEGRATED, PREDICTIVE EVOLUTIONARY APPROACH
}

\author{
John S. Torday \\ Evolutionary Medicine, Harbor-UCLA, Torrance, CA, USA
}

None of the extant theories of aging have proven to be effective in advancing our knowledge of senescence or mortality. In contrast to the gene-centric focus on evolution, the mechanism of cell-cell interactions as the driving force for evolution as the logic of biology is proposed. Since the distribution of bioenergy over the course of the life cycle is skewed towards the reproductive phase, bioenergy flags in the post-reproductive stage of life, causing failure of cell-cell signaling, loss of homeostatic control, senescence and death. In the interim, the phenotype acts as the 'agent' for epigenetic inheritance, obtaining 'marks' that inform the organism of changes in the environment. Such marks are inherited by the offspring, providing it with foreknowledge of the environment to come. The organism appears to 'return' to the unicellular state over the course of the life cycle, but in reality meiosis is the mechanism of epigenetic inheritance, the adult phenotype being the means for transmitting the epigenetic marks obtained from the environment back to the organism. Biomed Rev 2019; 30:15-21

Keywords: senescence; death; cell-cell communication; growth factor-receptor; phenotype as agent

\section{INTRODUCTION}

Over the course of the last thirty years, Medawar's mutation accumulation theory (1), Williams's antagonistic pleiotropy theory (2), and Kirkwood's disposable soma theory of aging (3) have formed the bases for evolutionary study of the genetic mechanisms of aging. However, none of these theories have proven to be consistently useful in predicting senescence or aging. Kirkwood (4) had more recently tried to reconcile the disposable soma and oxidative stress theories of aging and other mechanistic theories of aging, but was similarly unsuccessful.

Like so much of biology, any deeper understanding of aging has failed due to the dogmatic focus on genes as the be-all and end-all causal agents for evolution (5). Instead, it is argued that since cell-cell communication is the mechanistic driving force behind development and evolution as the 'logic of biology' (6), failure of cell-cell communication would predictably account for aging. In that vein, a novel process of aging is proposed.

Received 30 October 2019, revised 12 November 2019, accepted 14 November 2019.

Correspondence to: John S. Torday, Professor of Pediatrics, Obstetrics and Gynecology, Evolutionary Medicine, Harbor-

UCLA, Torrance, CA 20052, USA

Tel.: 310-433-6329; Email: jtorday@ucla.edu 


\section{WHY WE AGE}

Life began as negative entropy within the cell (7), and the positive entropy in the surrounding environment. Entropy is the amount of energy unavailable for work within the cell (8). That condition defies the Second Law of Thermodynamics. Ordinarily, entropy would increase if not for the bioenergy produced by chemiosmosis (9), controlled by homeostasis, or The First Principles of Physiology (10). Unicellular organisms dominated life on Earth for approximately 3.5 billion years prior to the advent of multicellular organisms about 500 million years ago (11). Multicellularity may have begun in reaction to pseudomulticellular traits of bacteria such as biofilm and Quorum Sensing. In response, eukaryotes, organisms with true nuclei, responded by cooperating metabolically, driven by rising levels of atmospheric oxygen (12).

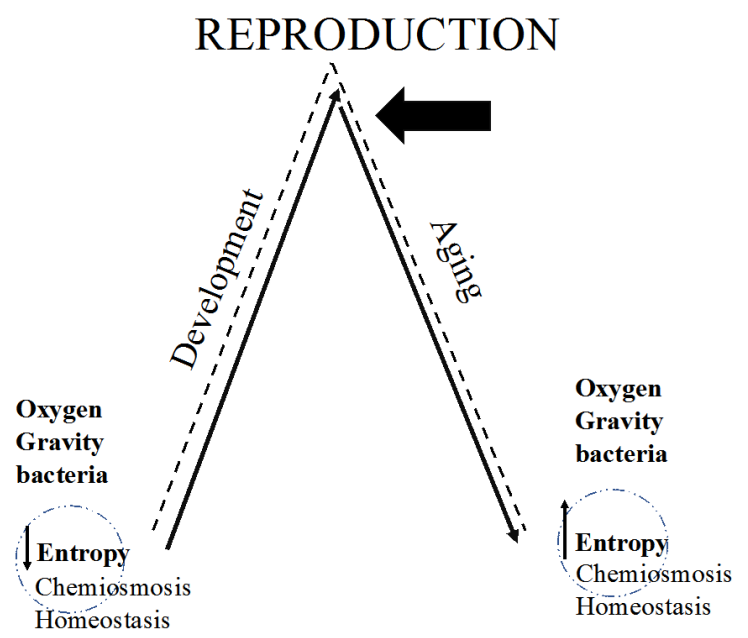

Figure 1. Bimodal life cycle and aging. Cell-cell signaling through growth factors and their cognate receptors mediates embryonic growth and differentiation, culminating in homeostasis (arrow points to the point at which homeostasis is reached; terminal addition is not relevant here, but is addressed in the text). That process reaches its peak during the fertile reproductive phase of life, hormones optimizing physiology to ensure reproductive success. Once the reproductive years are complete, the otherwise optimal bioenergetic state of the organism begins to break down since the amount of bioenergy is finite. This is what we describe as the Aging Process. And given that it is predicated on Terminal Addition, there is a resulting "programmed" sequence for the loss of cellular signaling for homeostasis, beginning with the most recently acquired traits - consciousness (dementia), thyroid function, and pulmonary function - all developing from the foregut, being the most common afflictions of aging.
We now know that oxygen in the atmosphere did not increase gradually from zero to $21 \%$, but instead fluctuated between 15 and $35 \%$ over the course of the Phanerozoic era (13). Much has been made about the cyclic increases in oxygen, which fueled giantism among animal life (14); but other than our work (12) no one has addressed the accompanying decreases in oxygen, which would have caused hypoxia, the most physiologically potent agonist known. That phenomenon has been exploited to explain the evolution of warm-blooded organisms, namely mammals and birds. Moreover, it was being warm-blooded that fostered bipedalism (15), freeing the forelimbs to fly, in the case of birds, or making tools in the case of Man, perhaps fostering speech in order to express one's self with hands 'full'. Those specialized traits are significant from an evolutionary perspective because both birds and mammals are deuterostomes, developing from the anus to the mouth. When that process is considered in light of Terminal Addition (16), the phenomenon by which the most recent module in a series of evolutionary changes literally appears at the end of the sequence. This occurs because intercellular ligand-receptor interactions mediated by intracellular 'second messengers' determine growth and differentiation of morphogenesis. Adding a new trait to a sequence of cell-cell signaling pathways at the end is a more sensible approach to evolutionary development than interpolating any of them within that series, undermining pre-existing adaptations. The cellular-molecular modularization of this process, when viewed as Terminal Addition, can thereby be seen as underpinning the developmental, phylogenetic and regenerative successes of evolution. Moreover, this perspective is consistent with the proximate nature of cell-cell interactions when growth factors are produced by the mesoderm, while their receptors reside on endodermal and ectodermal cells, thus governing the direction and magnitude of their communication. This perspective brings new light to human evolution and hypothetically bears on our understanding of aging (see below).

As described in Evolutionary Biology, Cell-Cell Communication and Complex Disease (12), the life cycle is bimodal (Fig. 1), cell-cell signaling through growth factors and their cognate receptors mediating embryonic growth and differentiation, culminating in homeostasis as the balance between said growth factors and their receptors (12). That process reaches its peak during the fertile reproductive phase of life, hormones optimizing physiology to ensure reproductive success (17). Once the reproductive years are complete, the otherwise optimal bioenergetic state of the organism begins to break down since the amount of bioenergy over the course of the life cycle is finite. This is what we describe as the Aging 
Process. And given that it is predicated on Terminal Addition, there is a resulting "programmed" sequence for the loss of cellular signaling for homeostasis, beginning with the most recently acquired traits - consciousness (dementia), thyroid function, and pulmonary function - all developing from the foregut, being the most common afflictions of aging (18). This step-wise retrograde dissolution of physiology is commonly referred to as 'healthy aging', whereas various diseases that can either undermine and/or accelerate the innate aging process are referred to as disease-based aging.

\section{DYING AND THE MICROBIOME}

Ultimately, we succumb to the aging process, and if we are buried in the ground, we decay, but our microbiome goes back to the soil, into the aquafer, assimilated by plants, eaten by animals, offering the opportunity to 'recycle' ourselves, as is thought in Eastern religions. The idea that our microbiome continues forward as part of a planetary cycle after death has been demonstrated, and is referred to as the necrobiome (19), or our bacterial 'footprint'. For this very reason, it behooves us to do our utmost to maintain our somatic health as the vehicle for our microbiome.

\section{PHENOTYPE AS AGENT}

The idea that we are vessels for our microbiome and the eukaryotic cell-type is consistent with the concept of the Phenotype as Agent (20). Based on Lamarckian epigenetic inheritance, instead of thinking conventionally of our phenotype as the totality of our biologic traits, it is our means of actively engaging with the environment and collecting what are called epigenetic 'marks'. Such marks are internalized by the organism and assimilated by the DNA of the egg and sperm through the addition of various chemical groups such as methylation, modifying its activity. During meiosis, such adducts are sorted for adaptive or maladaptive traits, and the adaptive marks are subsequently integrated into the offspring during the process of reproduction. The epigenetically inherited traits pre-tune the offspring to changes in the environment in order to adapt efficiently, providing a selection advantage for survival. Of course the final step is recognized as conventional Darwinian mate selection.

\section{THE RED QUEEN RUNNING IN PLACE, AND THE SINGULARITY}

Did you ever wonder why organisms return to their unicellular state during their life cycle? Because we are reasoning after the fact, seeing life from its ends instead of its means, we have misconstrued the sequence of events, much like thinking that the Earth as the center of the Solar System; once it was realized that the Sun was the center, many phenomena, like the cyclicity of Haley's Comet, returning every 75 years, were now predictable (21).

Similarly, by superimposing the mechanism of embryologic development on phylogeny, the process of evolution has also been deconvoluted (12). Based on that approach, complex physiologic traits have been traced back to their origin in the unicellular state (6) based on evolution as serial pre-adaptations, or exaptations (22). Given that principle, the question arises as to why the unicell itself evolved. Given the unity of the cell, the prequel would have been the putative Singularity that existed prior to the Big Bang (23), suggesting that the process of evolution is in service to the unicellular state as the point source of life (24), maintained and sustained by evolution (12), perpetually referencing the Singularity as the point source of the Cosmos.

To recap, with that perspective in mind, aging is the bioenergetic 'price' we pay for optimalizing reproduction, meiosis being the mechanism for endogenizing the epigenetic marks that inform the offspring of existential threats in the ever-changing environment (25). Overlaid by the reproductive strategy, honed by positive selection for reproductive success, the bioenergetics of the life cycle tend to shift towards the beginning of life when bioenergy is most abundant (17). Consequently, there is a shortage of bioenergy towards the post-reproductive stage, or end of life, since bioenergy is finite (26). Hence death.

\section{EPIGENETIC INHERITANCE AND AGING}

There is now emerging evidence that all organisms are able to inherit epigenetic marks from their environments, from unicellular (27) to multicellular (28). And it should be borne in mind that only $\sim 3-5 \%$ of human genetic diseases are Mendelian, leaving the other $95-97 \%$ to be of unknown origin- it is highly likely that they are epigenetic in nature. A priori, effective interaction with the environment optimizes the likelihood of keeping abreast of changes, given the ever-changing nature of the environment. As a result of bipedalism and its impact on evolution, birds and humans are able to occupy environments far more diverse than those of quadrupeds.

\section{NICHE CONSTRUCTION AS PHYSIOLOGY}

The key to understanding the aging process is in the intimate relationship between life, matter and the Cosmos. Perhaps nowhere better is that interrelationship seen than in the generation of ecosystems founded on the endogenization of factors in the environment, or Endosymbiosis Theory (29). The endogenization of existential threats such as heavy metals, ions, gases and bacteria, and their compartmentalization constitute endosymbiosis. In combination with Niche Construction Theory- that 
organisms modify their immediate environments like beavers building dams, or humans building homes, villages, towns, cities, nations, and finally Gaia, or Earth Mother- the cell as the first Niche Construction (30) forms a unified holistic system, cell physiology in sync with Quantum Mechanics (23), explaining how and why physics is the basis for life. But it must be seen emanating from the same Singularity/Big Bang diachronically, across space-time, not synchronically as a oneto-one relationship. That is to say, life 'transcends' space-time by circumventing the Laws of Nature using negative entropy (8), but only transiently, passing genetic and epigenetic information on to its progeny in order to perpetuate itself in adaptation to an ever-changing environment.

\section{CELL-CELL SIGNALING AS THE BASIS FOR EVOLUTION: INSIGHT TO AGING}

By superimposing developmental mechanisms of cell-cell signaling for structure and function on phylogeny, a novel understanding of evolution, beginning with its origin in the Singularity/Big Bang has emerged $(6 ; 12 ; 23)$. Evolution is a series of pre-adaptations or exaptations (22); tracing the cellcell signaling mechanisms for form and function backwards culminates in the unicellular state (6). When the question as to what preceded the cell arises, the Singularity prior to the Big Bang (31) seems the logical answer based on evolution as serial preadaptations. That perspective has given rise to the idea that aging is a consequence of the First Principles of Physiology (10) - negentropy, chemiosmosis, homeostasis - in combination with positive selection for reproductive success. That is to say, given that there is a finite amount of bioenergy over a life time (26), which is skewed towards the beginning of the life cycle to optimize reproductive success (17), bioenergy will run down post-reproductive stage. Loss of bioenergy results in failure to maintain cell-cell signaling for homeostasis, or what we think of conventionally as aging. That perspective would suggest that there is a 'logic' to the aging process that is overshadowed by the cumulative effects of disease. It would behoove us to separate out the natural mechanism of aging in order to better understand it.

\section{EXPERIMENTAL EVIDENCE FOR AGING AS LOSS OF CELL-CELL SIGNALING}

The hypothesis expressed in this article is that aging, senescence and death are due to the retrogressive failure of evolved cell-cell communications. For the sake of focus and efficiency, experimental evidence will be restricted to the three hormone receptors known to have duplicated during the water-land transition, namely the Parathyroid Hormone-related Protein
Receptor (PTHrPR), Glucocorticoid Receptor (GR), and Beta Adrenergic Receptor (Beta AR) (6).

There is experimental evidence for declines in PTHrPR levels in the aging rat duodenum (32), and lung (33). In bone, there are several studies showing decline in the response of bone to both endogenous $(34 ; 35)$ and a waning response of bone to exogenous PTHrP $(36 ; 37)$. Moreover, there is evidence of loss of bioactivity of PTHrP in regulating calcium activity in rat aortic smooth muscle (38).

Similarly, there is relatively extensive evidence for a decline in GR levels with aging (39 - 41). And as for the Beta Adrenergic Receptor, its levels also decline with age (42; 43).

These data are consistent with the effects of drugs like PPARgamma agonists, statins and rapmycin, all of which extend the lives of laboratory mice. The data for the effects on cell-cell signaling are limited.

\section{MALE-FEMALE DIFFERENCE AS PROOF OF PRINCIPLE FOR AGING AS LOSS OF CELL-CELL SIGNALING}

The premise of this article is that senescence and aging mirror development. Given that there is a relatively extensive literature on the role of androgens and Transforming Growth Factor $\beta$ in inhibiting development, and inferential data regarding the role of these in aging and senescence, the following is the proposed predicted role of androgens and Transforming Growth Factor $\beta$.

Men age and die earlier than women. And in birds, the opposite is the case. Many years of study of this phenomenon led to the realization that it is the homogametic sex that lives longer (44). That is to say that in mammals the female is homogametic (XX), whereas in birds the male is homogametic (ZZ). The standard explanation for the sex difference in longevity is that the $\mathrm{Y}$ or $\mathrm{W}$ chromosome, which determines the heterogametic sex lacks the balancing effect of genes on the $\mathrm{X}$ or $\mathrm{Z}$ chromosome, such that deleterious traits on the $\mathrm{Y}$ or $\mathrm{W}$ chromosome can cause premature senescence and demise. Moreover, it is the production of testosterone that inhibits development and accelerates senescence due to the stimulation of TGF $\beta$, which antagonizes growth factor-receptor signaling.

\section{WNT SIGNALING IS INDICATIVE OF LOST HOMEOSTATIC CONTROL}

The prototype for this mechanistic view on aging is as a continuum for the epithelial-mesenchymal interactions between epithelial and mesenchymal cells during embryogenesis (45). For example, during normal lung development, epithelialmesenchymal interactions generate the 40 different cell types that form the lung (46), culminating in homeostatic regulation 
for gas exchange (47). However, prematurity (48), mechanical over-distension (49), oxidative injury (50), and infection (51) can prevent or disrupt the full formation of the alveolus and homeostatic regulation. Under such circumstances, the mature regulatory pathway interconnecting the lipofibroblast and epithelial type II cell fails, and the lipofibroblast defaults to a myofibroblast, dominated by Wnt/beta Catenin signaling (52). Various agents have been used to experimentally prevent or treat the lung in order to recover or retain normal homeostatic control, as measured by the normal production of lung surfactant, the key molecule for alveolar homeostasis (53). The PPARgamma agonist Rosiglitazone has been shown to prevent or treat alveolar dyshomeostasis, inhibiting Wnt/ beta Catenin and up-regulating PTHrP Receptor expression to re-establish homeostasis as proof of principle (54).

Other tissues and organs like the kidney, liver, bone, and brain similarly form embryologically based on epithelial-mesenchymal interactions. Injury of the maturational pathway disrupts homeostatic control, and such agents as Rosiglitazone, Rapamycin, Statins and anti-inflammatory agents have been shown to prevent or restore homeostatic control. And since such properties of physiologic homeostasis are also disrupted during the process of aging due to loss of mitochondrial bioenergetics (55), similar reversion to Wnt/ beta Catenin signaling by the connective tissue cells occurs based on chronic lung disease as a model (56). And as in the case of the lung alveolus, various growth factor signaling agonists have been shown to either prevent the loss of homeostatic control or promote it, extending the life span of mice (57), for example.

\section{DISCUSSION}

The subject of aging has been debated for centuries, given the associated morbid and mortal consequences. To date there has been much speculation as to how and why we age and die based on descriptive biology. All such attempts are founded on the gene-centric view of biology (58), driven by the Darwinian view that evolution is due to random mutation and Natural Selection. However, that perspective is becoming more and more questionable (59), yet there has been nothing to supplant it in order to fulfill Dobzhansky's "Nothing in biology makes sense except in the light of evolution" (60), behooving us to solve the riddle, or suffer the consequences for all eternity (with apologies for the hyperbole). And for lack of any other perspective, we have been reasoning after the fact about evolution based on phylogeny. Yet developmental biology is the only mechanism known that generates the forms and functions that constitute Darwin's “endless forms most beautiful” (61).
Using contemporary embryology, Torday and Rehan (12) have exploited the Cell-Cell Communication mechanisms of growth factor-receptor signaling to deconvolute vertebrate evolution in a series of journal articles and books. Based on that approach, it has been hypothesized that aging is the natural consequence of the loss of bioenergy over the course of the life cycle beyond the peak reproductive stage (12). As a result, the mechanisms of cell-cell communication fail, resulting in senescence and death. See Commentary on pages 23-24.

If confirmed, this view of aging and dying is amenable to diagnosis and treatment, not so much as a disease, but as an insight of science as 'the only way we know what we don't know'. And once we have conquered aging, we will no longer fear it, and be stigmatized by it, instead being enabled to accept life on its terms as our means of being at one with the Cosmos (62).

\section{ACKNOWLEDGEMENT}

John S. Torday was a recipient of NIH Grant HL055268.

\section{REFERENCES}

1. Medawar PB (1952) An Unsolved Problem of Biology. London, H.K. Lewis \& Co.

2. Williams GC (1957). Pleiotropy, natural selection, and the evolution of senescence. Evolution 11:398-411.

3. Kirkwood T (1977) Evolution of ageing. Nature 270: 301-304.

4. Kirkwood TB (2005) Understanding the odd science of aging. Cell 120:437-447.

5. Futuyma D (1998) Evolutionary Biology. Sunderland, Sinauer Associates.

6. Torday JS, Rehan VK (2017) Evolution, the Logic of Biology. Wiley, Hoboken.

7. Torday JS, Miller WB Jr (2017) The resolution of ambiguity as the basis for life: A cellular bridge between Western reductionism and Eastern holism. Prog Biophys Mol Biol 131:288-297. doi: 10.1016/j.pbiomolbio.2017.07.013

8. Schrodinger E (1944) What is Life? New York, Macmillan.

9. Mitchell P (1961) Coupling of phosphorylation to electron and hydrogen transfer by a chemiosmotic type of mechanism. Nature 191: 144-148.

10. Torday JS, Rehan VK (2009) Lung evolution as a cipher for physiology. Physiol Genomics 38:1-6. doi: 10.1152/ physiolgenomics.90411.2008

11. Brunet T, King N (2017) The Origin of Animal Multicellularity and Cell Differentiation. Dev Cell 43:124-140. doi:10.1016/j.devcel.2017.09.016 
12. Torday JS, Rehan VK (2012) Evolutionary Biology, CellCell Communication and Complex Disease. Hoboken, Wiley.

13. Berner RA, Vandenbrooks JM, Ward PD (2007) Evolution. Oxygen and evolution. Science 316:557-558. DOI:10.1126/science.1140273

14. Payne JL, Groves JR, Jost AB, Nguyen T, Moffitt SE, Hill TM, Skotheim JM (2012) Late paleozoic fusulinoidean gigantism driven by atmospheric hyperoxia. Evolution 66:2929-2939. doi: 10.1111/j.1558-5646.2012.01626

15. Torday JS (2015) A central theory of biology. Med Hypotheses 85:49-57. doi: 10.1016/j.mehy.2015.03.019

16. Torday JS, Miller WB Jr (2018) Terminal addition in a cellular world. Prog Biophys Mol Biol. 135:1-10. doi: 10.1016/j.pbiomolbio.2017.12.003

17. Frisch RE (1994) The right weight: body fat, menarche and fertility. Proc Nutr Soc 53:113-129.

18. Aronson L (2019) Elderhood. New York, Bloomsbury Publishing.

19. Burcham ZM, Pechal JL, Schmidt CJ, Bose JL, Rosch JW, Benbow ME, Jordan HR (2019) Bacterial Community Succession, Transmigration, and Differential Gene Transcription in a Controlled Vertebrate Decomposition Model. Front Microbiol 10:745. doi: 10.3389/fmicb.2019.00745

20. Torday JS, Miller WB (2016) Phenotype as Agent for Epigenetic Inheritance. Biology (Basel) 5(3). doi: 10.3390/ biology5030030

21. Henry J (2001) Moving Heaven and Earth: Copernicus and the Solar System. Cambridge, Cambridge University Press.

22. Gould SJ, Vrba ES (1982) Exaptation- a missing term in the science of form. Paleobiology 8: 4-15.

23. Torday JS (2018) Quantum mechanics predicts evolutionary biology. Prog Biophys Mol Biol 135:11-15. doi: 10.1016/j.pbiomolbio.2018.01.003

24. Torday JS, Miller WB (2016) The Unicellular State as a Point Source in a Quantum Biological System. Biology (Basel) 5(2). doi: 10.3390/biology5020025

25. Haque MM, Nilsson EE, Holder LB, Skinner MK (2016) Genomic Clustering of differential DNA methylated regions (epimutations) associated with the epigenetic transgenerational inheritance of disease and phenotypic variation. BMC Genomics 17:418. doi: 10.1186/s12864016-2748-5

26. Hayflick L (2007) Biological aging is no longer an unsolved problem. Ann NY Acad Sci 1100:1-13.
27. Nowacki M, Landweber LF (2009) Epigenetic inheritance in ciliates. Curr Opin Microbiol 12:638-643. doi: 10.1016/j.mib.2009.09.012

28. Perez MF, Lehner B (2019) Intergenerational and transgenerational epigenetic inheritance in animals. Nat Cell Biol 21:143-151. doi: 10.1038/s41556-018-0242-9

29. Cazzolla Gatti R (2018) Endogenosymbiosis: from hypothesis to empirical evidence towards a Unified Symbiogenetic Theory Theor Biol Forum 111:13-26. doi: $10.19272 / 201811402002$

30. Torday JS (2016) The Cell as the First Niche Construction. Biology (Basel) 5(2). doi: 10.3390/biology5020019

31. Hawking S (1998) A Brief History of Time. New York, Bantam.

32. Gentili C, Morelli S, de Boland AR (2003) Characterization of PTH/PTHrP receptor in rat duodenum: effects of ageing. J Cell Biochem 88:1157-1167.

33. Kovacs T, Csongei V, Feller D, Ernszt D, Smuk G, Sarosi V, Jakab L, Kvell K, Bartis D, Pongracz JE (2014) Alteration in the Wnt microenvironment directly regulates molecular events leading to pulmonary senescence. Aging Cell 13:838-849. doi: 10.1111/acel.12240

34. Gardinier JD, Rostami N, Juliano L, Zhang C (2018) Bone adaptation in response to treadmill exercise in young and adult mice. Bone Rep 8:29-37. doi: 10.1016/j. bonr.2018.01.003

35. Zhang Y, Chen G, Gu Z, Sun H, Karaplis A, Goltzman D, Miao D (2018) DNA damage checkpoint pathway modulates the regulation of skeletal growth and osteoblastic bone formation by parathyroid hormone-related peptide. Int J Biol Sci 14:508-517. doi: 10.7150/ijbs.23318

36. Rachner TD, Hofbauer LC, Göbel A, Tsourdi E (2019) Novel therapies in osteoporosis: PTH-related peptide analogs and inhibitors of sclerostin. $J$ Mol Endocrinol 62:R145-R154. doi: 10.1530/JME-18-0173

37. Ricarte FR, Le Henaff C, Kolupaeva VG, Gardella TJ, Partridge NC (2018) Parathyroid hormone(1-34) and its analogs differentially modulate osteoblastic Rankl expression via PKA/SIK2/SIK3 and PP1/PP2A-CRTC3 signaling. J Biol Chem 293:20200-20213. doi: 10.1074/ jbc.RA118.004751

38. Ishikawa M, Ouchi Y, Akishita M, Kozaki K, Toba K, Namiki A, et al. (1995) Age-related decrease in the effect of parathyroid hormone-related protein on cytosolic free calcium level and tension in rat aortic smooth muscle. Naunyn Schmiedebergs Arch Pharmacol 351:517-522. 
39. Kalimi M (1984) Glucocorticoid receptors: from development to aging. A review. Mech Ageing Dev 24:129-138

40. Cristofalo V, Roberts J, Adelman R. (1972) Exploration in Aging. New York, Plenum.

41. Roth G, Hess G (1972) Changes in the mechanisms of hormone and neurotransmitter action during aging: current status of the role of receptor and post-receptor alterations. Mech Ageing Dev 20:75-194.

42. Ferrara N, Komici K, Corbi G, Pagano G, Furgi G, Rengo C, Femminella GD, Leosco D, Bonaduce D (2014) $\beta$-adrenergic receptor responsiveness in aging heart and clinical implications. Front Physiol 4:396. doi: 10.3389/ fphys.2013.00396

43. Scarpace PJ, Tumer N, Mader SL (1991) Beta-adrenergic function in aging. Basic mechanisms and clinical implications. Drugs Aging 1:116-129.

44. Torday JS, Nielsen HC (1987) The sex difference in fetal lung surfactant production.

Exp Lung Res 12:1-19.

45. Grobstein C (1967) Mechanisms of organogenetic tissue interaction. Natl Cancer Inst Monogr 26:279-299.

46. Warburton D, El-Hashash A, Carraro G, Tiozzo C, Sala F, Rogers O, et al. (2010) Lung organogenesis. Curr Top Dev Biol 90:73-158. doi: 10.1016/S0070-2153(10)90003-3

47. Whitsett JA, Weaver TE (2015) Alveolar development and disease. Am J Respir Cell Mol Biol 53:1-7. doi: 10.1165/ rcmb.2015-0128PS

48. Urs R, Kotecha S, Hall GL, Simpson SJ (2018) Persistent and progressive long-term lung disease in survivors of preterm birth. Paediatr Respir Rev 28:87-94. doi: 10.1016/j. prrv.2018.04.001

49. Rehan VK, Fong J, Lee R, Sakurai R, Wang ZM, Dahl MJ, Lane RH, Albertine KH, Torday JS (2011) Mechanism of reduced lung injury by high-frequency nasal ventilation in a preterm lamb model of neonatal chronic lung disease. Pediatr Res 70:462-466. doi:10.1203/ PDR.0b013e31822f58a1

50. Deuber C, Terhaar M (2011) Hyperoxia in very preterm infants: a systematic review of the literature. $J$ Perinat Neonatal Nurse 25:268-274. doi: 10.1097/ JPN.0b013e318226ee2c

51. Jobe AH (2016) Mechanisms of Lung Injury and Bronchopulmonary Dysplasia. Am J Perinatol 33:1076-1078. doi: $10.1055 / \mathrm{s}-0036-1586107$
52. Rehan V, Torday J (2003) Hyperoxia augments pulmonary lipofibroblast-to-myofibroblast transdifferentiation. Cell Biochem Biophys 38:239-250.

53. Cerny L, Torday JS, Rehan VK (2008) Prevention and treatment of bronchopulmonary dysplasia: contemporary status and future outlook. Lung 186:75-89. doi: 10.1007/ s00408-007-9069-z

54. Dasgupta C, Sakurai R, Wang Y, Guo P, Ambalavanan N, Torday JS, Rehan VK (2009) Hyperoxia-induced neonatal rat lung injury involves activation of TGF- $\{$ beta $\}$ and Wnt signaling and is protected by rosiglitazone. Am J Physiol Lung Cell Mol Physiol 296:L1031-L1041. doi: 10.1152/ ajplung.90392.2008

55. Wei YH, Lu CY, Wei CY, Ma YS, Lee HC (2001) Oxidative stress in human aging and mitochondrial diseaseconsequences of defective mitochondrial respiration and impaired antioxidant enzyme system. Chin J Physiol 44:1-11.

56. Torday JS, Rehan VK (2006) Up-regulation of fetal rat lung parathyroid hormone-related protein gene regulatory network down-regulates the Sonic Hedgehog/Wnt/beta catenin gene regulatory network. Pediatr Res 60:382-388.

57. Gómez-Linton DR, Alavez S, Alarcón-Aguilar A, LópezDiazguerrero NE, Konigsberg M, Pérez-Flores LJ (2019) Some naturally occurring compounds that increase longevity and stress resistance in model organisms of aging. Biogerontology 20:583-603. doi: 10.1007/s10522-01909817-2

58. Khan AH, Zou Z, Xiang Y, Chen S, Tian XL (2019) Conserved signaling pathways genetically associated with longevity across the species. Biochim Biophys Acta Mol Basis Dis 1865:1745-1755. doi: 10.1016/j.bbadis.2018.09.001

59. Steves CJ, Spector TD, Jackson SH (2012) Ageing, genes, environment and epigenetics: what twin studies tell us now, and in the future. Age Ageing 41:581-586. doi: 10.1093/ageing/afs097

60. Dobzhansky T (1973) Nothing in biology makes sense except in the light of evolution. Am Biol Teacher 35:125129.

61. Darwin C (1859) On the Origin of Species. London, John Murray.

62. Torday JS (2019) The Singularity of nature. Prog Biophys Mol Biol 142:23-31. doi: 10.1016/j.pbiomolbio.2018.07.013 